\title{
REMOTE AUTOMATION SYSTEM CONTROL USING ARDUINO BOARD
}

\author{
Kusay F. Al-Tabatabaie ${ }^{1}$, Koraw Dara Hama²
}

\begin{abstract}
This research paper aims to design a smart home system by utilizing Wireless Local Area Network (WLAN) based on Android mobile operating systems and Arduino microcontroller. The system is able to monitor and control room temperature, lights, alarms and other house appliance. Test bed shows proper controlling and monitoring functionalities to a network using Blynk application. It gives powerful support for special needs of the elderly and people with disabilities.
\end{abstract}

Keywords - Smart home automation; Arduino; android mobile; Blynk server.

\section{INTRODUCTION}

Smart home automation system is not a new term with science, society however; currently no smart home system exists on cheaper rates. Some of the systems are hard to install, challenging to use and maintain. Existing systems are generally patented and closed, not very customizable by the end user. Automation system uses Arduino device which is an open-source prototyping platform based on easy-to-use hardware and software [1], support allows external USB hardware (an Android USB accessory) to cooperate with an Android-powered device in a special accessory mode. If the Android-powered device is switched to accessory mode, the linked accessory proceeds as the USB host (powers the bus and enumerates devices) and the Android-powered device runs in the USB accessory role. Where the accessory mode depends on the device's hardware, not all devices supports accessory mode [2]. A model of the electrical device control system using Web had been designed by [3], he also set the server with auto restarts if the server condition is currently down. For that, Wi-Fi supported home automation system is viewed [4]. It applied a PC (with built in Wi-Fi card) based on a web server that controls the connected home devices. A similar architecture is proposed in [5] where the actions are coordinated by the home agent running on a PC, also [6]. Google and Microsoft also have entered the home automation domain. At the $2011 \mathrm{I} / \mathrm{O}$ conference, Google announced Android@Home. The first standard Android devices to communicate with external hardware were introduced by Google. Where Android applies Open Accessory Standard and the Accessory Development Kit (ADK) which is a key of communicating with hardware and building external accessories for Android devices, it had been used in research like [2]. Other papers such as [7]; [8] also presented internet controlled systems consisting of a dedicated web server, database and a web page for the linking and controlling with the devices. A model for home automation using Bluetooth via PC or mobile technology had been explained in [9] but unfortunately the system is hard to apply. Currently there are numbers of ongoing studies with using Arduino device applications such as [10]; [11]; [12]; [13]; [14] and others. This paper displays an automation system which includes a remote mobile as a host controller and a client module. The client modules communicate with the host controller of an Ethernet device enabled an android based smart mobile phone to control sensors. Although automation today is not a new thing, but most advanced home automation systems in existence today require a big and expensive change of infrastructure. The proposed automation system that can control LED (light Emitted Diode), ultrasonic sensor, heat sensor using mobile. In this low cost, secure cell phone based, flexible automation system is introduced. Devices are connected to the Arduino web server. The communication between the cell phone and the Arduino boarded using an

\footnotetext{
${ }^{1}$ Computer Science Department Cihan University - Sulaimanya Campus, Sulaimanya, Iraq
}

${ }^{2}$ Computer Science Department Cihan University - Sulaimanya Campus, Sulaimanya, Iraq 
Ethernet connection. Additional devices can be connected to the system with little modifications. The cell phone will be Android.

\section{Architecture Of Arduino Mega 2560}

The Arduino Mega is the type of microcontroller which have been used for this project. It has low-power CMOS 8bit microcontroller based on the AVR enhanced RISC architecture. By executing powerful instructions in a single clock cycle, the mega 2560 achieves throughputs approaching 1 Minute Per Second per MHz allows the system design to optimize power consumption of processing speed (Official Arduino website). The Mega 2560 architecture is as shown in Fig. 1.

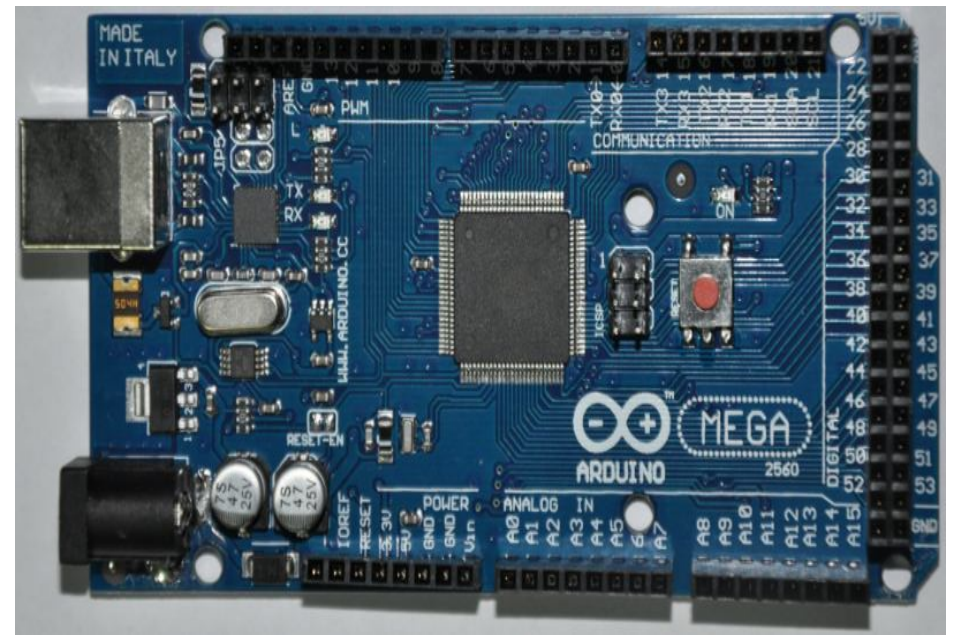

Figure 1 Arduino Mega 2560 Architecture.

Where figure 1 shows all pins outputs, digital, analog, power and ground, were detailed as shown in table 1.

The board of Arduino Mega 2560 applications could be used for Embedded Design \& Development; Industrial; Communications \& Networking; Sensing \& Instrumentation; Automation \& Process Control. The recommended range is between $7 \mathrm{~V}$ and $12 \mathrm{~V}$, in case more than $12 \mathrm{~V}$ has been used, it may overheat the voltage regulator and damage the board.

Table. 1. Technical specification for Arduino Mega 2560 (Official Arduino website).

\begin{tabular}{|l|l|}
\hline Microcontroller & ATmega2560 \\
\hline Operating Voltage & $5 \mathrm{~V}$ \\
\hline Digital I/O Pins & 54 (of which 15 provide PWM output) \\
\hline Analog Input Pins & 16 \\
\hline DC Current per I/O Pin & $20 \mathrm{~mA}$ \\
\hline DC Current for 3.3V Pin & $50 \mathrm{~mA}$ \\
\hline Flash Memory & $\begin{array}{c}256 \mathrm{~KB} \text { of which 8 KB used by the boot - } \\
\text { loader }\end{array}$ \\
\hline SRAM & $8 \mathrm{~KB}$ \\
\hline EEPROM & $4 \mathrm{~KB}$ \\
\hline Clock Speed & $16 \mathrm{MHz}$ \\
\hline Length & $101.52 \mathrm{~mm}$ \\
\hline Width & $53.3 \mathrm{~mm}$ \\
\hline
\end{tabular}




\section{Methodology}

The proposed system was distributed among home automation system, consists of server, hardware interface modules. Server controls hardware one interface module, and can be easily configured to handle more hardware interface module. The hardware interface module in turn controls ultrasonic sensor, motion sensor, light sensor, LED, and thermal sensor. A server is a normal PC, with an Ethernet card, performs as a web server. The web server software is expanded using asp.net technology, so web server must support asp application and.net frame work 4.0, like IIS7.0 for windows OS. System can be logged in from the web browser using any local PC in the same LAN by server IP, or it can access remotely from any PC or mobile handheld device connected to the internet with appropriate web browser supports asp.net technology through server real IP (internet IP). Ethernet card is selected to be the network infrastructure that connects server and hardware interface modules. The main purpose of the server is to manage, control, and monitor suspected system components, that enables hardware interfaces modules to execute their assigned tasks (through actuators), and to report server with triggered events (from sensors). The methodology has been divided into two stages:

1. Proposed module design, this experiment consists of two main parts, the software programs interface and the hardware for different applications.

2. The software program interface is the program and the way of connections between the hardware parts and the Arduino.

The hardware parts include: Computer, Arduino, Bread board, LED, Sensors, Relays, and wires as shown in Figure 2.

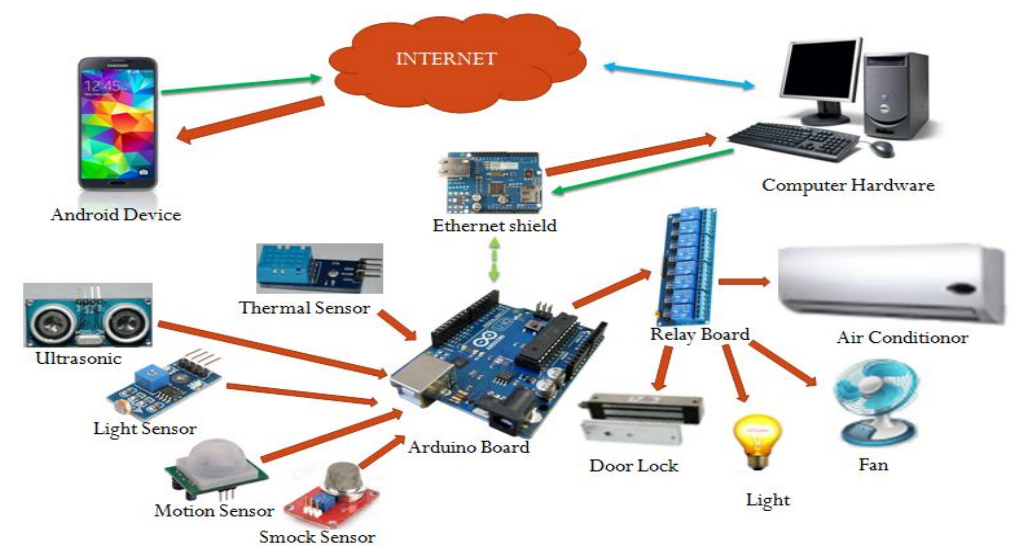

Figure 2 Project design module.

When Arduino setup mode, user will be able to add and remove hardware interface modules, also can create basic macros involving simple triggers and to modify the macros to execute complex sequence of events. It is possible to activate macros manually or by reaction for certain trigger like surveillance cameras and motion sensors. It is also possible for user to program macros by activating at random; this feature permits the system to turn the lights on and off at random or semi-random periods. While in running mode, if hardware interface components report server with received events and perform their pre-programmed macros. Hardware interface modules are directly connected to sensors and actuator through direct wires connections. The modules have the abilities to control energy management systems like lighting, thermostats and HVAC (heating, Light sensor, and cooling) systems, and security systems (door locks, motion detectors, fire alarms...).

Regarding software concept, at the beginning of the project, programs have been run and tested for each sensor without using Ethernet shield and Internet, it was basically just connected to the Arduino and look to the responding of sensors value. Then, programs have been designed based on that responding.

In this project, initially LED had been used as a replacement of any kind of light that can be used in a house, also for testing different results, as well as find actions and reactions of the sensors. The user begins with getting access to the system then, perform the desired action from the GUI. Switching actions can be performed either manual or through voice recognition activation that uses the Google Speech Recognition engine available on the device. The software responds as shown in Figure3. 
When the user performs an action on the smart home application, command packet will be sent through internet to the micro web-server. The micro web-server could extract and read the information about the command packet easily.

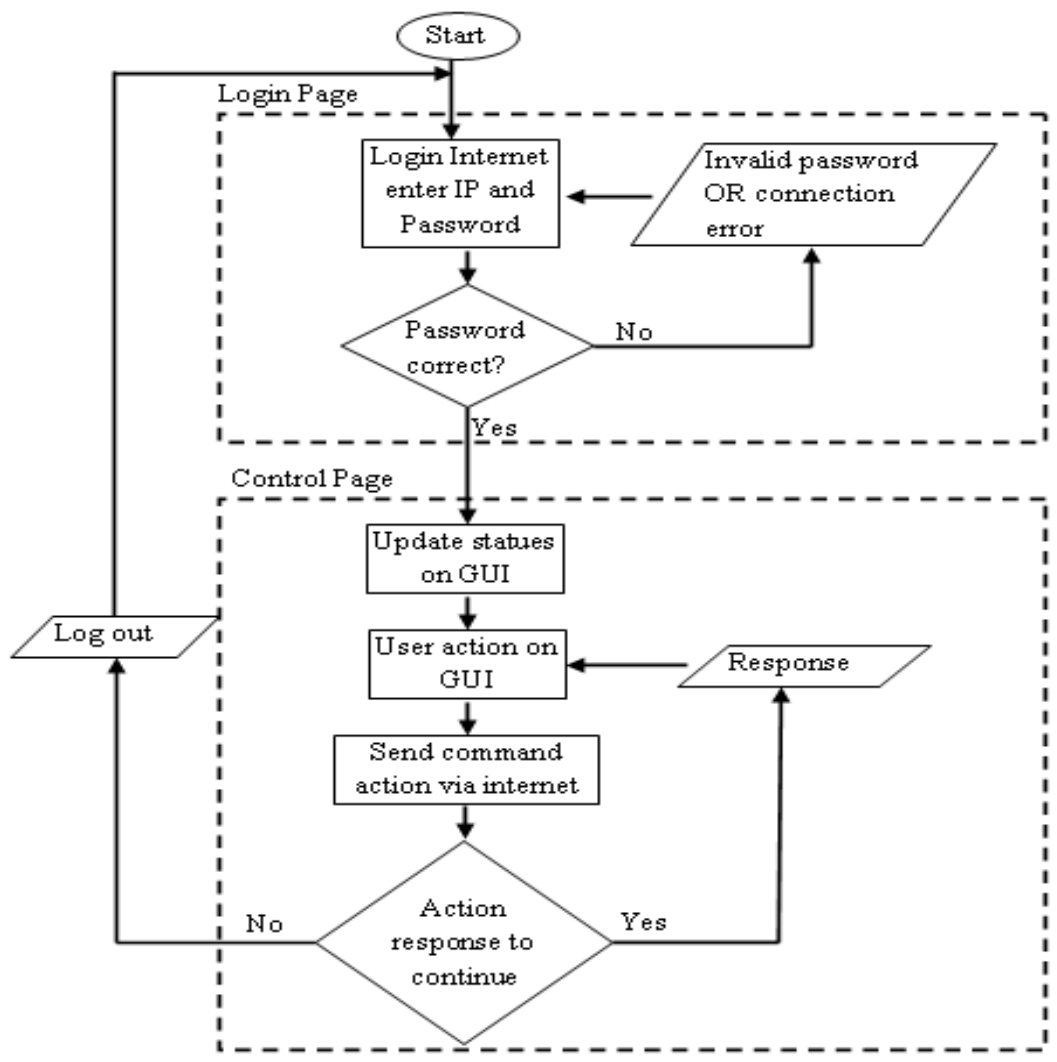

Figure 3 Response process of designed automation system.

\section{RESULTS AND DISCUSSION}

This research implemented using the Arduino connected with Ethernet shield as a micro web server, which can be connected to the hardware module architecture. The system receives status updates and sends control information on the microcontroller, passing information on it as codes. The information could be received using Android phone to turn on or off lights and sensors. The smart home system responds are showing in this section to verify that system was fully developed and tested to demonstrate its feasibility and effectiveness. The hard work and efforts that put in this project that led us to achieve remarkable results. The findings where as following stapes: Before start with results needs to make sure that hardware is linked online. By having the Blynk Library installed on the computer, example Sketches will help in getting hardware to be online quickly and major Blynk features.

Open the example sketch according to the hardware model or the used shield could be as shown in Figure4. 


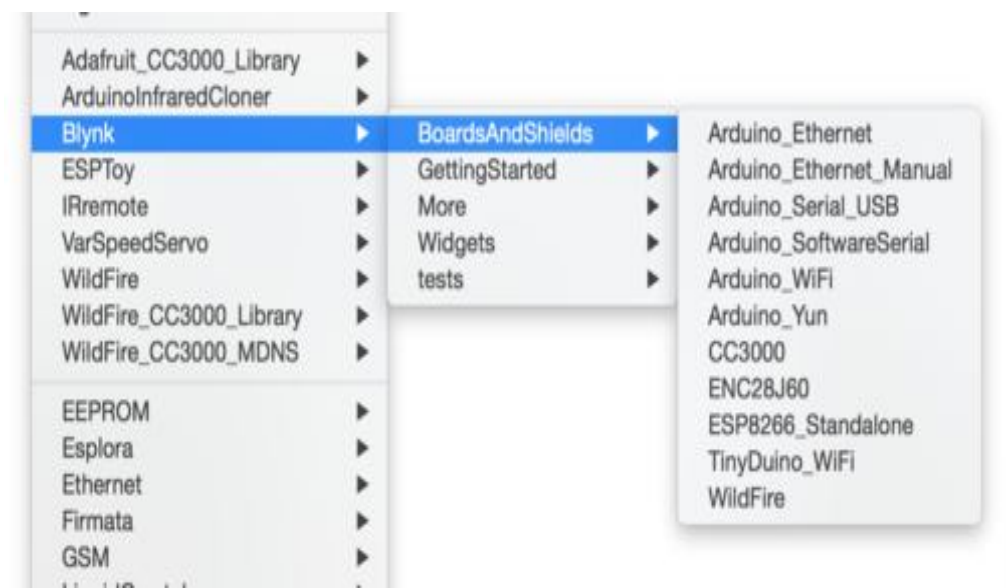

Figure 4 the example Sketch for an Arduino Mega2560 with Ethernet shield 2.

The return email from Auth Token needed to be copy and paste it inside the quotation marks as shown in Figure5.

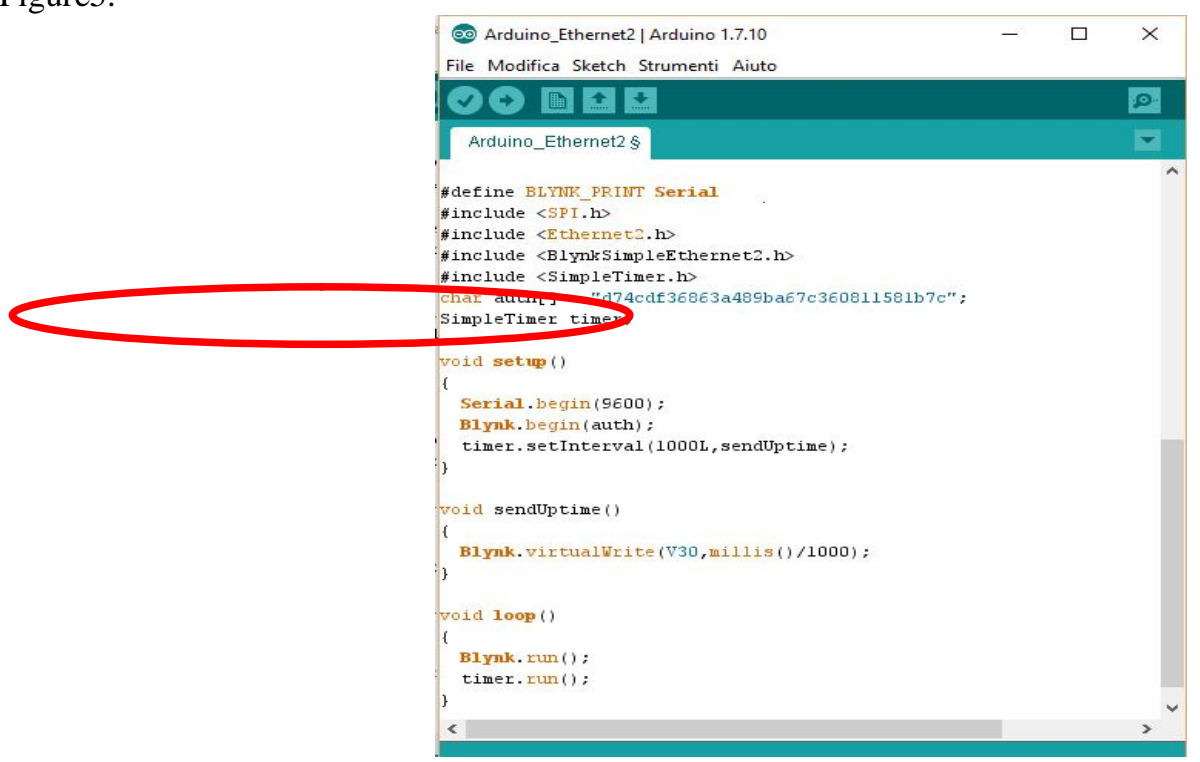

Figure 5 Arduino code for home automation system shows Auth Token copied and pasted it inside the quotation marks.

The Sketch needed to be uploaded on board and open Serial Terminal. Then, wait until obtaining something as shown in Figure6.

\section{Blynk v.X.X.X \\ Your IP is $192.168 \cdot 0.11$ \\ Connecting... \\ Blynk connected!}

Figure 6 Message tells that hardware is connected to the Blynk Cloud.

For testing, needs to return back to the Blynk Application, push the button and turn the LED on and off, It should be Blynking as shown in Figure7. 


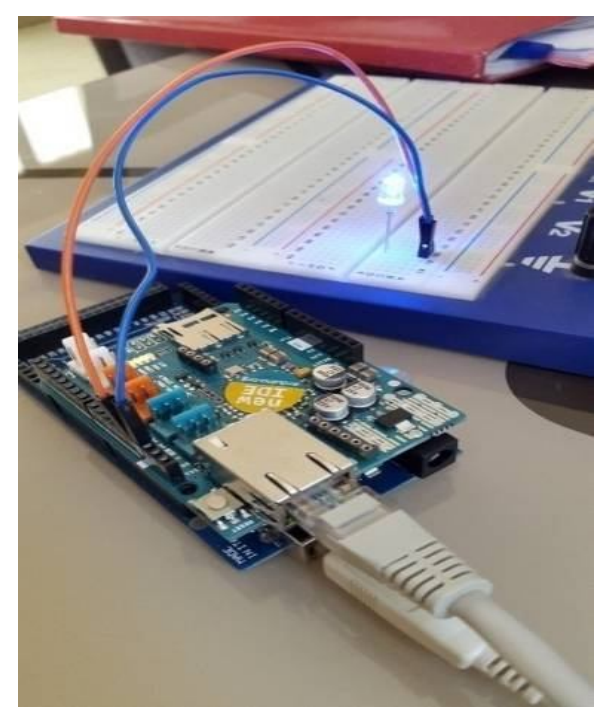

Figure 7 Getting started with hardware.

Light emitting diode response: Using Blynk application by Android in figure 8A could give order to turn the light on or off as figure $8 \mathrm{~B}$.

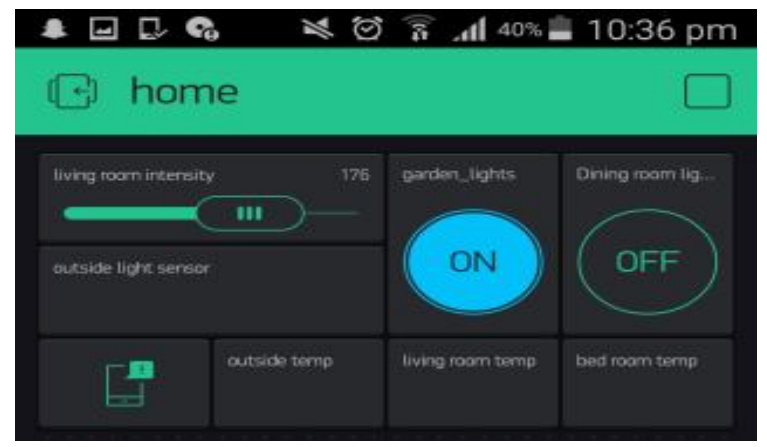

Figure 8 Blynk application Android.

For light sensor response, as for Light sensor response is shown in the Figure9 the light sensor are connected to an Analog pin of the Arduino board and can read and monitor the value of the light intensity in the Blynk app to show if it is dark or light.

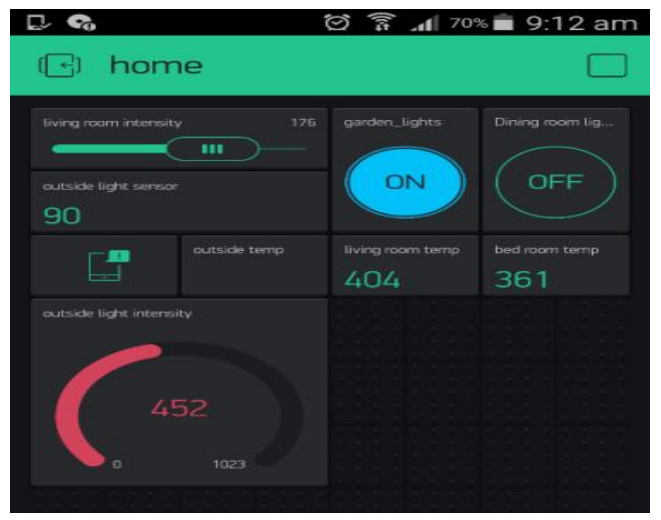

Figure 9 Blynk application monitoring the light intensity.

This light sensor can be put outside the house to turn on and off the lights when it is day or night. Similarly, the testing could be done for other sensors. 


\section{Conclusions}

This research was conducted to design and improve the standard living at home with low cost, to control various home applications and provide secure, ubiquitously accessible, auto-configurable, remotely controlled solution. This work is focused on Android and Arduino platform, both of them are connected FOSS (Free Open Source Software). The remote control function by smart phone Android, which provides help and assistance especially to disabled and elderly peoples, any android supported device can be used to install the smart home application, and control and monitor the smart home environment. In order to design to consist of Android phone with the home automation application, Arduino Mega ATmega2560 had been used. The user can interact with the Android phone and send control signal to the Arduino Mega which in turn will control other embedded devices/sensors. Moreover, implementation of Ethernet card connection with control board allows the system installed in a simplest way.

The planed aims at home automation system have been accomplished. Where system designed and architecture had been discussed, and basic level of home appliance control prototype had been presented with implementing remote monitoring. However, it could be expanded upon many other areas in the future by not restricting to only home. It could be flexible to support various wired as well as wireless technologies like Bluetooth, Zigbee, and Wi-Fi.

\section{REFERENCES}

[1] Official Arduino website: www.arduino.cc

[2] D. Javale, M. Mohsin, S. Nandanwar, and M. Shingate (2013), "Home Automation and Security System Using Android ADK". International Journal of Electronics Communication and Computer Technology (IJECCT) Volume. 3, Issue, 2.

[3] M. I. Ramli, M. H. A. Wahab, N.N. Ahmad (2006), "Towards Smart Home: Control Electrical Devices Online", International Conference on Science and Technology: Application in Industry and Educatio.

[4] A. ElShafee, and K. A. Hamed (2012), " Design and Implementation of a WiFi Based Home Automation System", World Academy of Science, Engineering and Technology, Vol:6.

[5] R. D. Caytiles, and B. Park (2012), "Mobile IP-Based Architecture for Smart Homes," International Journal of Smart Home, vol. 6, pp. 29-36.

[6] F. Kausar, E. A. Eisa, and I. Bakhsh (2012), "Intelligent Home Monitoring Using RSSI in Wireless Sensor Networks," International Journal of Computer Networks \& Communications, vol. 4, pp. 33-46.

[7] A. Rajabzadeh, A. R. Manashty, and Z. F. Jahromi (2010), "A Mobile Application for Smart House Remote Control System", World Academy of Science, Engineering and Technology, vol. 62.

[8] U. Sharma, and S. R. N. Reddy (2012), "Design of Home/Office Automation Using Wireless Senosr Network," International Journal of Computer Applications, vol. 43, pp. 53-60.

[9] R.A.Ramlee, M.H.Leong, R.S.S.Singh, M.M.Ismail, M.A.Othman, H.A.Sulaiman, M.H.Misran, and M.A.Meor Said (2013), "Bluetooth Remote Home Automation System Using Android Application"The International Journal of Engineering And Science (IJES), Vol. 2, Issue: 01, Pages: 149-153 (ISSN: 2319 - 1813 ISBN: 2319 - 1805).

[10] S. Kumar (2014). "Ubiquitous Smart Home System Using Android Application". International Journal of Computer Networks \& Communications (IJCNC) Vol.6, No.1.

[11] N. K. Sonawane, P. D.Waghchavare, and K. A. Patel (2014), " Bluetooth Based Device Automation System Using Cellphone". International Journal of Computer Applications \& Information Technology Vol. 7, (ISSN: 2278-7720).

[12] N. David, A. Chima, A. Ugochukwu, and E. Obinna (2015), " Design of a Home Automation System Using Arduino", International Journal of Scientific and Engineering Research Vol:6, Isue:6 •

[13] B. Murlikishna, V. Narasimahanayak, K. Ravishorereddy, B. Rakesh, P. Manojkumar, and N.Sandhya (2015), " Bluetooth Based Wireless Home Automation System Using FPGA", Journal of Theoretical and Applied Information Technology, Vol.77. No.3.

[14] P. B. Patil, R. R. Patil, S.V.Patil, and A. R.Telepatil (2016), " Home Automation System Using Android and Arduino Board", International Journal of Innovative Research in Science, Engineering and Technology, Vol. 5, Issue: 4. 